
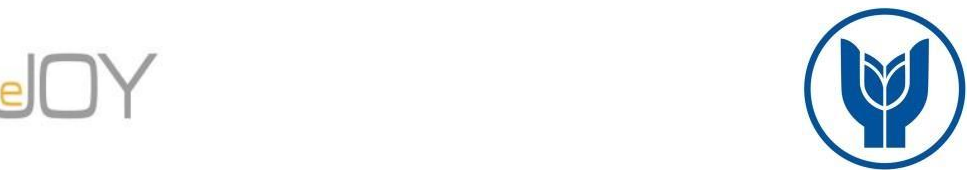

Kesbiç, C. Y., Çevik, S. / Journal of Yasar University, 2021, 16/64, 1624-1641

\title{
Döngüsel Ekonomi Göstergelerinin Türkiye Ve Seçili Latin Amerika Ülkelerine Gerçekleştirilen Doğrudan Yabancı Yatırımlar Üzerine Etkisi: Bir Ekonometrik Analiz Örneği
}

\section{The Effect of Circular Economic Indicators on Foreign Direct Investment Which Are Conducted Turkey and Selected Latin America Countries: An Example of Econometric Analysis}

\author{
Cüneyt Yenal KESBİÇ, Celal Bayar Üniversitesi, Türkiye, c.yenalkesbic@ gmail.com \\ Orcid No: 0000-0001-8894-6439 \\ Suna ÇEVİK, Celal Bayar Üniversitesi, Türkiye, suna.cevik@gmail.com \\ Orcid No: 0000-0003-40-73-6680
}

\begin{abstract}
$\ddot{O ̈}_{z}$ : Bu çalışmada amaç döngüsel ekonominin içerdiği kabul edilen sürdürülebilirlik, enerji, teknoloji ve inovasyon, insani gelişme kavramlarını temsil eden değişkenlerin uluslararası yabancı sermaye yatırımların bir türü olan doğrudan yabancı sermaye yatırımları üzerine etkisini analiz etmektir. Çalışmada Türkiye ve 11 adet Latin Amerika örnekleminde doğrudan yabancı yatırımlar (DYY kısaltması kullanılacaktır) ve döngüsel ekonomi süreçleri ele alınmıştır. Ekonometrik analiz çalışmasında 2000-2018 veri dönemi seçilerek Türkiye ve 11 adet Latin Amerika ve Karayipler ekonomileri (Brezilya, Arjantin, Bolivya, Şili, Kolombiya, Ekvador, Panama, Paraguay, Peru, Uruguay, Venezuela) örneklem olarak seçilmiştir. Çalışmada Panel VAR modeli kurulmuş, homojen genel panel VAR modelinin anlamlı olmadığ belirlenmiştir. DYY üzerinde genel olarak Granger nedensellik testi anlamı bulunmuş, DYY’lerin teknoloji değişkeni üzerinde pozitif ve anlaml etki sahibi olduğu, teknoloji ve insani gelişme değişkenlerinin karşılıklı pozitif anlamlı etki sahibi olduğu Granger nedensellik testi ile ortaya konmuştur.
\end{abstract}

Anahtar Sözcükler: Döngüsel Ekonomi, Doğrudan Yabancı Yatırımlar, Sürdürülebilirlik, Enerji, Teknoloji, Inovasyon

\author{
JEL Sinıflandirması: F21, O11, O54, O33, Q55
}

\begin{abstract}
This article aim is to analyze the effects of variables representing sustainability, energy, technology and innovation and human development notions which are assessed circular economy included in the circular economy, on foreign direct investment, which is a type of international foreign capital investment. In the study, foreign direct investments (the abbreviation FDI will be used in this article) and circular economy processes are discussed in the samples of Turkey and 11 Latin America. In the econometric analysis study, the 2000-2018 data period has been selected, and Turkey and 11 Latin American and Caribbean economies (Brazil, Argentina, Bolivia, Chile, Colombia, Ecuador, Panama, Paraguay, Peru, Uruguay, Venezuela) has been selected as samples. In the study, the Panel VAR model has been established and the homogeneous model has been determined to be unsignificant. The result of Granger causality test on FDI has been found significant in general, and it has been revealed by Granger causality test that FDIs have a positive and significant effect on the technology variable, and that technology and human development variables have a mutually positive and significant relationship.
\end{abstract}

Keywords: Circular Economy, Foreign Direct Investments, Sustainability, Energy, Technology, Innovation

JEL Classification: F21, O11, O54, O33, Q55

\section{Giriş}

Döngüsel ekonomi kavramı, fiziksel olayların ve doğal döngülerin gözlemlenmesine dayanır. Lavoisier'e atfedilen "hiçbir şey kaybolmaz, hiçbir şey yaratılmaz, her şey dönüştürülür", bu ünlü söz genellikle döngüsel ekonominin en iyi özeti olarak kabul edilir. Presokratik Yunan 
filozofu Anaxagoras tarafindan 1789 Elementary Treatise of Chemistry adlı eserinden aktarılan bu ifade bir fikrin yeniden formülasyonu olmuştur: "hiçbir şey varolmaz veya yok edilmez, ancak var olan şeylerin karışması ve ayrılması vardır". Kavram, ancak doğrusal ekonomiye karşıtlığına dayanmaktadır. (Institut Montaigne, 7-8; 2016).

Döngüsel ekonomi odak noktaları olarak belirlediği tasarım, üretim, tüketim ve yeniden kullanımda çevresel sürdürülebilirlik, sıfır atığa ulaşma hedefi, yeniden kullanım, kaynak kullanımında israfı azaltma, hammadde kullanımını azaltma vb. çeşitli amaçlar bakımından tanımlanabilmektedir. Çevre ve Enerji Yönetimi Ajansı (ADEME), döngüsel bir ekonominin genel amacını, kaynak kullanımını GSYİH büyümesinden ayırmak için kaynak israfını önemli ölçüde azaltmak ve aynı zamanda çevresel etkilerin sınırlı olmasını ve refahın korunmasını sağlamak olarak belirler. Bu, daha azıyla daha çok ve daha iyi yapmanın bir örneğidir." şeklinde ifade eder. Ellen MacArthur Vakfı döngüsel ekonomiyi şu şekilde tanımlamaktadır: "Döngüsel ekonomi, tasarım gereği onarıcı ve yenileyici olan ve teknik ve biyolojik döngüler arasında ayrım yaparak ürünleri, bileşenleri ve malzemeleri her zaman en yüksek fayda ve değerde tutmayı amaçlayan bir döngüdür. Yaratıcıların öngördüğü gibi, döngüsel ekonomi, doğal sermayeyi koruyan ve geliştiren, kaynak verimlerini optimize eden ve sinırlı stokları ve yenilenebilir akışlart yöneterek sistem risklerini en aza indiren sürekli bir pozitif gelişme döngüsüdür. Her ölçekte etkili bir şekilde işe yaramaktadır" (Institut Montaigne, 10; 2016).

Doğrusal ekonomi sisteminden döngüsel ekonomiye geçiş süreci devam etmektedir; bu süreci hızlandırabilmek için gerçekleştirilecek eylemler için uygulanacak beş ilke a)Yeniliğe odaklanma b)Teklif ve talebe ilişkin kapsamlı, küresel bir yaklaşım benimsemek, c)Sektörler arasındaki farklılıklar ve kamu/özel işbirliğinin geliştirilmesi d)İlerlemeyi ölçmek: tüm değer zincirini kapsayan güvenilir göstergeler geliştirmek, e)Daha gelişmiş ülkelerle sınırlı kalmamak şeklinde ifade edilebilir (Institut Montaigne, 4-5; 2016). Gelişmiş ve gelişmekte olan ekonomilerde dönüşüm ekonomisin uygulama ve kapsam farkının olması doğaldır. Avrupa ve Latin Amerika arasında döngüsel ekonomi kavram anlayış farklılıkları bulunur. Farklılıkların kaynağının Avrupa olduğu ve Avrupa bu geçişte çok daha uzun süre kalmasına rağmen Latin Amerika'nın büyük ilgi gösterdiği ancak bu bölgenin başka engellerle karşı karşıya olduğu tespit edilmiştir. Avrupa'nın kültürel ve politik kısım gibi kademeli olarak üstesinden geldiği, ayrıca Latin Amerika, değişim yaratma hevesiyle, Avrupa'nın döngüsel ekonomiyi geri dönüşüm ve atık yönetimi yoluyla ekonomik değer üretmeye bir alternatif olarak sunarak, Latin Amerika'da döngüsel ekonomiye verilen yaklaşımla ilgili olan uygulama hatalarını tekrarlamaktadır (Betancourt Morales ve Sossa, 2020). Latin Amerika ve Karayipler'de, Bridgetown, 1 Şubat 2021 itibariyle Barbados'da ilan edilen, bölgede döngüsel ekonomiye 
geçişin teşviki için bir destek olan, Döngüsel Ekonomi Koalisyonu hükümetler ve özel sektör tarafindan desteklenen bir yapıda inovasyon kaynak seferberliği ve bölgede projeleri desteklemek amacıyla, yeni dönemde COVID-19 toparlanmasının bir parçası olarak kurulmuştur. Eko-tasarım tarafından yönlendirilen döngüsel bir ekonomi, atıkları ve kirliliği ortadan kaldırır, ürünleri ve malzemeleri kullanımda tutar ve doğal sistemleri yeniden oluşturur. UNEP'in Uluslararası Kaynak Paneline göre, bu ilkelerin benimsenmesi, hammadde kullanımını \%99'a kadar azaltarak biyolojik çeşitliliğin korunmasına katkıda bulunabilir. Koalisyon, hükümetler, işletmeler ve bir bütün olarak toplum arasında işbirliği yoluyla döngüsel bir ekonomi yaklaşımı uygulamayı hedeflemektedir (UNIDO, Brazil, 2021).

Latin Amerika ve Karayipler bölgesinde Birleşmiş Milletler Sınai Kalkınma Organizasyonu (UNIDO) ve Birleşmiş Milletler Çevre Programı (UNEP) çeşitli yerel, bölgesel ve uluslararası kurum ve kuruluşlarla ortaklık ve iş birliği içerisinde Milenyum Kalkınma Amaçlarından (MDG) -özellikle 7.si- sürdürülebilirlik ve çevre amacı kapsamında çeşitli projeler ve programlar geliştirmişlerdir. Bu projeler ve programlar döngüsel ekonomi iş modellerini gerçekleştirmek için önemli unsurlar olan teknoloji, inovasyon, temiz yenilenebilir enerji ve çevresel sürdürülebilirliği sağlamak adına gerçekleştirilmiştir. Bu projelerden biri UNIDO, Ulusal Jeolojik, Madencilik ve Metalurji Araştırma Enstitüsü, INIGEMM (Ekvador), Peru Çevre Bakanlığı ve ABD Dışişleri Bakanlığı kurumları tarafından Ekvador ve Peru'da “Artisanal Altın Madenciliğinden Cıva Salınımlarını En Aza İndirmek İçin Entegre Önlemlerin Uygulanması" adıyla Ekim 2012 - Eylül 2015 tarihleri arasında Küresel Çevre Kurumu (GEF): US\$ 999,900 Eş- Finansman: US\$ 2,676,764 bütçe ve bağışı ile gerçekleştirilmiştir (https://www.unido.org/who-we-are/unido-worldwide/latin-america-and-caribbean/selectedunido-field-projects 10.05 .2021$)$.

Türkiye'nin döngüsel ekonominin gerekli unsurlarından çevresel sürdürülebilirlik ve temiz sınai gelişim sürdürülebilir kalkınma erişilebilir ve yenilenebilir enerji alanlarında uluslararası kurumların işbirliğiyle gerçekleştirilen proje ve programların katılımcısı olduğu bilinmektedir. Bunun önemli bir örnegi Birleşmiş Milletler Sınai Kalkınma Organizasyonu (UNIDO)'nun Viyana'da 1966 yılında kuruluşundan bir yıl sonra 1967 yılında Türkiye şubesi ile faaliyete başlamasıdır. Halihazırda yürütülen yedi adet proje vardır. Bunlardan biri 6.510.050,00 USD Bütçeli Montreal Protokolü'dür. Proje, Montreal Protokolü gereklilikleri ve Ulusal ODS Aşamasının hazırlanmasına ilişkin Montreal Protokolünün Uygulanmasına ilişkin Çok Taraflı Fonun ilgili yönergeleri doğrultusunda ülkenin HCFC (Hidro kloroflorokarbonlar) Aşamadan Çıkarma Yönetim Planını (HPMP) geliştirmeyi amaçlamaktadır (UNIDO, 2021). Sürdürülebilir kalkınma anlayışının kaynakların sınırı olduğunu bir bakıma göz ardı eden 
günümüz doğrusal ekonomi sisteminde Türkiye'de döngüsel ekonomi alanında gerçekleştirilen akademik çalışmaların 2010'dan sonra artış gösterdiği ve bu artışın görece küçük bir kısmının doktora düzeyinde olduğu bilinmektedir. Bunun temel sebebi sürdürülebilirlik paradigmasında yaşanan değişimle birlikte döngüsel ekonomi kavramının popüler hale gelmesinin 1990'lı yıllardan sonra gerçekleşmesinden kaynaklandığı ifade edilebilir (Yalçın, Negiz, 2020). Türkiye Teknoloji Geliştirme Vakfı (2014), yakın gelecekte, temiz üretim kavramının çevre yönetimi ve verimlilik ile ilgili çalışmalarla çok daha sarmal bir yapı haline geleceğini öngörmektedir. Bu konuda geliştirilen uluslararası projeler, düzenlemeler, ülkesel bazda alınan önlemler, teşvikler, sürdürülebilir kalkınmanın önceliklerinden birinin temiz teknoloji kullanmak ve temiz üretim proseslerine sahip olmaktan geçtiğini göstermektedir (Cüce; 2018).

Doğrudan yabancı sermaye yatırımları uluslararası sermaye akımlarının bir türüdür. Uluslararası ekonomi literatüründe "DYSY" teriminde geçen "Yabancı" kelimesi bir ülkenin milli sınırları dışında olmak anlamındadır. Karluk (1999) tanımıyla "Yabancı Sermaye" bir ülkedeki mevcut sermaye stokuna başka bir ülkenin sahipliğini ifade etmelidir. "Doğrudan" kelimesi ise sermaye ile birlikte değişen ölçüde teknoloji, know-how (teknik bilgi) ve işletmecilik bilgisinin de ülkeye geldiğini açıklamaktadır (Batmaz ve Tekeli, 2009). Bu bilgiler 1şığında DYSY’yi (çalışmada DYY kısaltması kullanılmıştır) Şahinöz (1998)'ün belirttiği şu şekilde tanımlamak mümkündür: "Doğrudan yabancı sermaye yatırımları, yabancı sermaye yatırımlarının özel bir türü olup, yabancıların dış ülkelerde kalıcı çıkar elde etmek amacıyla fiziki, ekonomik varlıklar üzerinde tam ya da kısmi mülkiyet hakkı ve denetim sahibi olmalarlyla sonuçlanan yatırımlardır.” (Batmaz ve Tekeli, 2009).

DYY'nin diğer sermaye kalemlerinden farklı bir yönü de büyümeye doğrudan katkısının yanı sıra dolaylı uzun dönem etkilere de yol açabilmesidir. Berthelemy ve Demurger (2000) ile Borensztein, De Gregorio ve Lee (1998) tarafindan belirtildiği üzere DYY, yönetim teknikleri ve teknolojiye ilişkin bilginin -özellikle yeni sermaye girdileri biçiminde- ülkelerarası transferini hızlandırarak, yerli iş gücünün yaparak öğrenme ve eğitime olan yatırımlar yoluyla yeteneklerini geliştirmesine katkıda bulunmaktadır (Babaoğlu, 2005). DYY'nin doğrudan etkileri giriş şekline göre farklılık arz etse de ilk olarak doğrudan üretime katkısı ve giriş yapan ilk defaya mahsus yabancı sermayenin girişi ile ödemeler bilançosu kalemlerine pozitif katkı sağlaması sayılabilir.

UNCTAD'ın 1998 yılı dünya yatırım raporunda (WIR); DYY'yi etkileyen faktörlere ilişkin yaptığı analizlerde de ortak birtakım görüşlerin savunulduğu görülmekte olup buna ilişkin bir analize yer verilmiştir (Batmaz ve Tekeli, 2009). Ev sahibi ülke açısından doğrudan yabancı yatırımların etkilendiği faktörler UNCTAD tarafindan yayınlanan 1998 yılı Dünya Yatırım 
Raporu'nda politik faktörler, yatırım ortamına ilişkin faktörler ve ekonomik faktörler başlıkları altında sinıflandırılmaktadır.

1970'lerin başından bu yana, Latin Amerika'ya DYY girişleri GSYİH'nın \%1'inden \%4'üne yükselmiştir. 1970'lerin başında, Latin Amerika en az gelişmiş ülkelerdeki DYY'nin \%53'ünü alırken, Afrika \%34 ve Asya \%10'unu almıştır. 2000'lerin sonlarında Asya \%64 ve 2000'lerin sonunda \%12 Afrika ile birlikte, DYY'den LDC'lere doğru zaman içinde kaymış olsa da, Latin Amerika 2000'lerin sonlarında \%25 olmak üzere hala önemli bir miktar almaktadır. Latin Amerika'nın DYY giriş payını Çin'in DYY giriş payı ile karşılaştırmak da önemlidir. Latin Amerika, Asya (Çin hariç) ve Çin için LDC'lere toplam DYY girişlerinin payını incelendiğinde 2000'lerin başında (2000-04), DYY girişlerinin payı Latin Amerika ve Çin için sırasıyla 33 ve 24'e eşitti. 2000'lerin sonunda Çin'in payı \%18'e düşmüştür ve Latin Amerika'nın payı 25'e yükselmiştir. Asya'ya ve özellikle Çin'e artan DYY akışlarına rağmen, Latin Amerika bölgesi EAGÜ'lere toplam DYY'nin büyük bir kısmını almaya devam etmektedir (Blanco, 2012) . Latin Amerika'da 2000-2001 yıllarında, muhtemelen 1999'daki makroekonomik temellerdeki istikrarsılılı, 2000 Arjantin krizi ve 2001 ABD durgunluğu nedeniyle DYY'de büyük bir düşüş olmasına rağmen, eğilim genel olarak olumlu olmuştur. Toplam DYY'nin payı olarak kirlilik yoğun DYY eğilimi bu payın zaman içinde nispeten istikrarlı olduğunu göstermektedir. (Blanco vd., 2013). Dünya yatırım Raporu'nun (WIR, 2018) belirttiği üzere Güney Amerika'ya yapılan DYY, iki önde gelen ekonomi olan Arjantin ve Brezilya'daki durgunlukların sona ermesiyle $\% 10$ artmıştır. Arjantin'e akış, ekonomik toparlanma ve yatırımları çekmek ve altyapıyı geliştirmek için yeni politikaların getirilmesiyle üç kattan fazla artarak 11,9 milyar dolara ulaşmıştır. Brezilya'ya yapılan DYY \%8 artarak 62,7 milyar dolara yükselmiştir. Brezilya, bölgedeki en büyük ekonomidir ve toplam akışın yüzde 40'ından fazlasını Latin Amerika'ya çekmektedir. Bölgedeki yabancı şirketlerin en büyük 10 satın alımından (7 tanesi Çinli alıcı olan) dokuzu Brezilya'da gerçekleşmiştir. Şili'deki yatırım 6,7 milyar dolara gerilemiştir.

Ekonomi Bakanlığı Teşvik ve Uygulama ve Yabancı Sermaye Genel Müdürlüğü, Uluslararası Doğrudan Yatırımlar 2014 Yılı Raporu'nda açıklandığı üzere Türkiye’ye gelen toplam uluslararası doğrudan yatırım tutarı 1975-2004 döneminde sadece 19,6 milyar USD düzeyinde iken, 2005-2014 yılları arasında 8 kattan fazla artarak 144,3 milyar USD’ye ulaşmıştır. 2014 yılında ise Türkiye, Dünya genelinde uluslararası doğrudan yatırımlarda bir önceki yıla göre 4 basamak yükselerek 22. sıraya yerleşmiştir. Bununla birlikte jeopolitik risklere ve Ortadoğu'daki çalkantılı ortama rağmen Türkiye'nin, 2013 yılında olduğu gibi 2014 yılında da Batı Asya Bölgesi'nin en fazla doğrudan yatırım çeken ülkesi olması, bu durum ülkenin uluslararası yatırımcılar nezdindeki güvenli liman vasfına ve Türkiye'nin iş ortamı 
anlamında da uluslararası konjonktüre gösterdiği uyuma vurgu yapmaktadır. Daha sonra gerçekleşen bölgesel riskler ve politik istikrarsızlıklar doğrudan yabancı yatırım girişlerinde de azalışın nedenlerinden olmuştur. Dünya yatırım Raporu'nun (WIR, 2018) belirttiği üzere Batı Asya'daki diğer büyük DYY alıcısı olan Türkiye, 2007-2015 döneminde alt bölgeye toplam girişlerin dörtte birinden fazlasını oluşturmuştur. DYY girişleri, 2016'daki önemli düşüşün ardından 2017'de 11 milyar dolara düşmeye devam etmiştir. Batı Asya için yaklaşık on yı1 boyunca devam eden aşağı yönlü eğilimin değişip 2018 yılında bölgesel olarak \%3 artış ile 29 milyar dolar olmasında Türkiye'nin DYY miktarının yükselmesinin de etki sahibi olduğu belirtilmiştir. Türkiye yavaşlayan ekonomik büyüme TL'deki belirsizliğe rağmen 2018 yılında yaklaşık \%13'lük bir artış ile 13 milyar dolar DYY çekmiş ve bölgede DYY'nin \%90'ını absorbe eden dört ülkeden biri olmayı sürdürmüştür (WIR, 2019).

Ekonomik büyüme ve doğrudan yabancı yatırımlar arasındaki ilişkiyi inceleyen oldukça fazla sayıda çalışma bulunmaktadır. Tam bir literatür birliği bulunmamasına rağmen ekonometrik analiz içeren çalışmaların önemli bir kısmı (Borensztein vd.;1995, Balasubramanyam vd.;1996, Bengoa ve Robles;2002, Choe;2003, Hsiao ve Shen;2003, Li ve Liu;2004, Chowdhury ve Mavrotas;2005, Roy ve Den Berg;2006, Alfaro ve Charlton;2007, AlIrani;2007, Okuyan ve Erbaykal;2007, Örnek;2008, Karimi ve Yusop;2009, Azman-Saini vd.;2010, Koyuncu;2011, Behname;2011, Umoh vd.;2012, Guechang ve Molio;2013, Emir ve Kutlu;2014) DYY ve ekonomik büyüme arasında pozitif ve anlamlı ilişki olduğunu ortaya koymaktadır. Literatürdeki bu durum DYY'lerin ekonomik büyüme ve ekonomik büyümenin DYY üzerinde etki sahibi olduğu savını güçlendirmektedir. $\mathrm{Bu}$ nedenle çeşitli döngüsel ekonomi göstergelerinin ekonomik büyüklük üzerine etkisini test etmek için seçilen bağımlı değişsken doğrudan yabancı yatırımlar olmuştur.

\subsection{Literatür Araştırması}

Literatür araştırmalarına bakıldığında doğrudan yabancı sermaye yatırımlarının çeşitli ekonomik göstergeler üzerindeki etkisini ve çeşitli ekonomik göstergelerin doğrudan yabancı sermaye akımları üzerindeki belirleyiciliğini konu alan çok sayıda araştırma mevcuttur. Ancak döngüsel ekonominin belirleyici kriterleri olarak alınan teknoloji kapasitesi, inovasyon ve sürdürülebilir insani gelişmeye ilişkin değişkenlerin doğrudan yabancı sermaye yatırımları üzerindeki etkilerini araştıran literatür oldukça sınırlıdır. Bu çalışmada amaç döngüsel ekonominin göstergeleri olarak kabul edilebilen teknoloji ve inovasyon, enerji erişimi ve kullanımı ve insani gelişmeye yönelik göstergelerin doğrudan yabancı sermaye yatırımları üzerindeki etkisini araştıran literatüre katkı sağlamaktır. Addison ve Hesmati (2003) gelişmekte 
olan ülkeleri örneklem aldıkları araştırmalarında 1980'lerin başında başlayan “üçüncü dalga demokratikleşme" ve 1980'lerin sonunda yayılan bilgi ve iletişimde gerçekleşen gelişmelerin DYY'nin girişlerini arttırdığını panel veri yöntemi ile sınayarak ortaya koymuşlardır. Başçı Nur ve Dilber (2018) DYY belirleyici faktörleri panel veri ekonometrik analiz yöntemi ile sınadıkları çalışmalarında teknoloji değişkeni için ileri teknoloji ihracatının toplam imalat sanayi ihracatı içindeki oranını gösteren veri setini dikkate almışlardır. Teknoloji değişkeni adı altında kullanılan imalat sanayi ürünleri ihracatı içinde ileri teknoloji ürünlerinin ihracat payı verisini çalışmaya alarak ülkede mevcut beşeri sermayenin kalitesi ile ilgili fikir sahibi olmaya çalışılmaktadır. Analiz sonucuna göre söz konusu verideki \%1'lik artış, DYY’yi \%0,5 arttırmaktadır. Karagöz (2007) Türkiye'de doğrudan yabancı yatırımların belirleyicilerini 1970-2005 veri dönemi için araştırdığı çalışmasında altyapı yatırımların değişkeni alt kapsamında enerji ve ulaştırma alanındaki kamu yatırımlarının payının olumlu belirleyiciliğe sahip olduğunu tespit etmiştir. Albulescu vd. (2019) 14 Latin Amerika ülkesini 1980-2010 dönemi için inceledikleri çalışmalarında düşük karbon salınımı seviyesi için DYY'nin çevresel bozulmaya etkisinin negatif olduğunu belirlemişlerdir, bunun anlamı Paraguay Nikaragua ve Honduras gibi Latin Amerika ülkelerine gelen çokuluslu şirketler çevre dostu teknolojiler getirmişlerdir. Diğer bir yandan da karbondioksit salınımı gelir düzeyi artışı ile artmış ancak kişi başına gelir artışı dikkate değer şekilde gerçekleştikten sonra azalmıştır. Fakat bu teyit, yüksek karbon salınımı olan ülkeleri için bulgular çok daha düşük geçerlilikte iken, düşük düzeyde karbon salınımı olan ekonomiler için geçerli olmuştur. Bulgulara göre yapılan politika uygulama önerilerinde DYY'nin çevresel bozulma üzerinde herhangi belirgin bir etkisi bulunmadığı için, temiz ve enerji verimlisi yatırımları çekmek için düzenlemelerin tasarlanmasının zor olduğudur. Ancak düşük karbon seviyesinde olan ülkeler için, DYY çevresel bozulmayı önlemek için teşvik edilmelidir. Haug ve Ucal (2019) Türkiye örnekleminde 1973-2011 veri kısıtında Doğrusal olan ve doğrusal olmayan ARDL Modeli ekonometrik analiz yöntemi ile DYY co2 değişkeni üzerinde uzun dönemde etki sahibi olmadığını bulmuşlardır. Seker vd. 2015, DYY'ler ile birlikte toplam gayri safi yurtiçi hasıla ve toplam gayri safi yurtiçi hasılanın karesi ve enerji tüketiminin, karbondioksit salınımı üzerindeki etkisini Türkiye örnekleminde 1974-2010 veri dönemi için araştırmışlardır. ARDL modelinin uzun dönemli katsayılarının toplam gayri safi yurtiçi hasıla ve enerji tüketimi değişkenlerinin karbondioksit salınımının üzerinde dikkate değer etki sahibi olduğunu belirlerken DYY'lerin karbondioksit salınımı üzerinde pozitif fakat göreli olarak küçük bir etkiye sahip olduğunu belirlemişlerdir. Araştırmadan elde edilen bulgular; Türkiye'nin enerji verimliliği ile sürdürülebilir büyümeyi teşvik etmesi gerektiğini, özellikle teknoloji yoğun 
alanlarda ve çevre dostu endüstrilerde DYY iç akışlarını, çevresel kaliteyi iyileştirmek için desteklemesi gerektiğini göstermektedir. Chor ve Bee (2015), araştırmalarında karbondioksit emisyonu, enerji tüketimi, DYY ve ekonomik büyüme değişkenleri arasındaki ilişkileri Vietnam örneklemi için 1976-2009 veri dönemi içerisinde eş bütünleşme ve Granger nedensellik analizi yöntemleri ile incelediklerinde gelir ve karbondioksit salınımı, DYY ve karbon salınımı arasında çift yönlü ilişki tespit etmişlerdir. Enerji tüketimi karbondioksit salınımının kısa ve uzun dönemde granger nedeni olarak belirlenmiştir. Enerji tüketimi DYY ve gelir düzeyi Vietnam'da karbon salınımının temel belirleyicileridirler. Bu nedenle, temiz teknolojilerin yabancı yatırım tarafından benimsenmesi, ülkedeki CO2 emisyonlarının azaltılması ve aynı zamanda ekonomik kalkınmanın sürdürülmesi açısından önemlidir.

\section{Ekonometrik Analiz}

\subsection{Ekonometrik Yöntem}

Bu araştırmada değişkenler panel veri ekonometrik analiz yöntemi ile incelenmiştir. Öncelikle değişkenlerin heteroskedasitesine bakılmış model sınanmış ve homojen olduğu belirlenmiştir. Daha sonra yatay kesit bağımlılı̆̆ı bir diğer deyiş ile değişkenler arası korelasyonun varlığına yönelik test gerçekleştirilmiş ve birimler arasında yatay kesit bağımlılığı olduğu belirlenmiştir. Bu nedenle ikinci grup panel birim kök testleri panel birim kök sınaması için tercih edilmiştir, testlerden elde edilen veri panel birim kök varlığını doğrulamıştır. Uygun panel VAR modelini kurabilmek için uygun gecikme uzunluğu 1 olarak belirlenmiştir. İçselliği göz önüne alan dinamik panel VAR modeli olduğu için ileri ortagonal sapmalar kullanan Holtz-Eakin, Newey ve Rosen GMM tahmincisi tercih edilerek Panel VAR modeli kurulmuş, birinci farklarında durağan olduğu önceden belirlenen değişkenler arasında, panelin homojen olduğu da göz önünde bulundurularak, nedensellik ilişkisinin varlığını test etmek için Granger nedensellik analizi gerçekleştirilmiştir. Öngörü hatası varyans ayrıştırması için test gerçekleştirildikten sonra etki tepki fonksiyonları analizi ve özdeğer istikrar koşulları da kısa dönemli analizi tamamlamak amacıyla gerçekleştirilmiştir.

Çalışmada doğrudan yabancı yatırımlar üzerinde bilgi ve iletişim teknolojileri kapasitesi (ict), enerji kapasitesi (en) ve insani gelişme endeksi (hdi) ilk olarak

$\mathrm{dyy}_{\mathrm{t}}=\mathrm{f}\left(\mathrm{ict}_{\mathrm{t}}, \mathrm{en}_{\mathrm{t}}, \mathrm{hdi}_{\mathrm{t}}\right)$ şeklinde daha sonra serileri durağanlaştırmak amacıyla birinci farkları alınarak

ddyy $_{i t}=\mathrm{f}\left(\operatorname{dict}_{i t}, \operatorname{den}_{i t}, \operatorname{dhdi}_{i t}\right)$ şeklinde fonksiyonel olarak ifade edilmiştir.

Eşitlikte $i(\mathrm{i}=1 \ldots \ldots \mathrm{N})$ ülkeleri, $t(t=1 \ldots \ldots \ldots)$ zamanı göstermektedir. 
Modelde kullanılan tüm değişkenler 2000-2018 veri dönemi için belirlenmiştir. Modelde bağımlı değişken doğrudan yabancı yatırımlar iç akışları, yıllık yüzde olarak değişimi (dyy, birinci dereceden farkı alındığında kısaltma ddyy) veri kaynağı The WorldBank, doğrudan yabancı yatırım net cari ABD doları cinsinden girişlerinin yıllık \% değişim değerleri bağımlı değişkendir. Veriler cari ABD doları cinsinden DYY girişlerinin yıllık \% değişim değerleri alınmıştır. Üretim Kapasitesi Endeksi, Bilgi ve İletişim Teknolojileri (ict, dict), kaynak UNCTAD. Bilgi ve İletişim Teknolojisi (BİT): Bilgi ve İletişim Teknolojisi, nüfus içindeki iletişim sistemlerinin erişilebilirliğini ve entegrasyonunu tahmin eder. Sabit hat ve cep telefonu kullanıcıları, internet erişimi ve sunucu güvenliğini içerir. Üretim Kapasitesi endeksi, Enerji (en, den) kaynak UNCTAD. Enerji: Bu kategori, güç kaynaklarının kullanılabilirliğini, sürdürülebilirliğini ve verimliliğini ölçer. $\mathrm{Bu}$ nedenle, enerji kullanımı ve erişimi, enerji bileşenlerinin ve kaynaklarının dağıtımı ve yenilenebilirliğindeki kayıplardan oluşur ve optimum enerji sistemlerinin önemini daha da vurgulamak için her bir petrol birimi tarafindan üretilen GSYİH'yi içerir. İnsani Gelişme Endeksi (hdi, dhdi) kaynak UNDP. İGE, insani gelişmenin üç temel boyutundaki uzun dönemli ilerlemeyi değerlendirmek için kullanılan özet bir ölçüm yöntemidir. Bu üç temel boyut; uzun ve sağlıklı yaşam, bilgiye erişim ve insana yakışır bir yaşam standardı olarak sıralanmaktadır.

\subsection{Yapilan Testler}

Tablo 1. Birimler Arası Korelasyon İçin Pesaran'ın CD Testi

\begin{tabular}{|c|c|c|c|c|}
\hline Değişkenler & $C D$ & Olasılık Dĕ̌eri & corr & abs(corr) \\
\hline ddyy & 0.17 & 0.862 & 0.005 & 0.215 \\
\hline$d h d i$ & 5.24 & 0.000 & 0.152 & 0.213 \\
\hline den & 3.80 & 0.000 & 0.110 & 0.195 \\
\hline dict & 14.51 & 0.000 & 0.421 & 0.421 \\
\hline
\end{tabular}

Paseran'ın (2004) birimlerarası korelasyon testi gerçekleştirilmiştir. Modelin birim değişkenleri arasında korelasyon ilişkisi olasılık değerinin 0.05 'den büyük olması nedeniyle vardır. $\mathrm{H}_{0}$ hipotezi reddedilmiş ve birimler arası korelasyonun var olduğu anlaşılmıştır. Değişkenlerin birinci dereceden farkları alınarak uygun birim kök testine karar verilebilmesi için serilerde birimler arası korelasyon varlığı Peseran'ın CD testi ile sınanarak belirlenmiştir. Birimler arası korelasyon katsayıları sirasıyla $0.215 ; 0.213 ; 0.195 ; 0.421$ 'dir. 
Tablo 2. Durağanlık Analizi için Peseran CIPS Testi

\begin{tabular}{|c|c|c|c|c|c|c|}
\hline Değişkenler & $t$-bar & $c v 10$ & $c v 5$ & $c v 1$ & Z[t-bar] & $P$-value \\
\hline$d d y y$ & -4.132 & -2.140 & -2.260 & -2.470 & -8.091 & 0.000 \\
\hline$d h d i$ & -2.673 & -2.140 & -2.260 & -2.470 & -3.134 & 0.001 \\
\hline$d e n$ & -2.877 & -2.140 & -2.260 & -2.470 & -3.826 & 0.000 \\
\hline dict & -2.665 & -2.140 & -2.260 & -2.470 & -3.107 & 0.001 \\
\hline
\end{tabular}

Yapılan CIPS testinde serilerin birinci farkları alınmış değişkenlerinin durağan olduğu görülmektedir. P olasılık değerleri 0.05'in altında gerçekleşmiştir. Gerçekleştirilen Peseran'nın birimler arası korelasyonun varlığında panel birim kök testidir.

Tablo 3. Homojenliğin Testi

\begin{tabular}{|c|c|c|c|c|c|c|}
\hline ddyy & Coef. & Standart Hata & $z$ & $P>|z|$ & \multicolumn{2}{|c|}{ [95\% Conf. Interval] } \\
\hline$d h d i$ & -568.9493 & 10296.2 & -0.06 & 0.956 & -20749.14 & 19611.24 \\
\hline den & 106.197 & 138.4283 & 0.77 & 0.443 & -165.1174 & 377.5114 \\
\hline dict & -84.7827 & 230.4783 & -0.37 & 0.713 & -536.5118 & 366.9464 \\
\hline sabit terim & 24.54312 & 84.418 & 0.29 & 0.771 & -140.9131 & 189.9994 \\
\hline $\begin{array}{l}\text { Parametre } \\
\text { Sabitliği Testi: }\end{array}$ & \multicolumn{2}{|l|}{ KiKare (44) 30.92} & & & & \\
\hline
\end{tabular}

Birinci dereceden farkları alınmış değişkenler analizde kullanılmak üzere seçilmiştir, daha sonra bir gecikmeli Panel VAR modelinin her iki eşitliğinin tesadüfi katsayılar modeli ile tahminlendiği görülmektedir. Parametre homojenliğini sınamaya yönelik çıktıların en altında yer alan Swamy $\mathrm{S}$ testi sonuçlarına göre her iki model için $\mathrm{H}_{0}$ hipotezi kabul edilmiş parametrelerin homojen olduğuna karar verilmiştir. Panelin homojen olduğuna karar verildiği için homojen panel nedensellik testi ve homojen panel VAR analizi tercih edilmiştir. 
Tablo 4. Panel VAR Modeli İçin Uygun Gecikme Uzunluğu Tablosu

\begin{tabular}{|c|c|c|c|c|c|c|}
\hline Gecikme & $C D$ & $J$ & J pvalue & MBIC & MAIC & MQIC \\
\hline 1 & 1 & 64.02433 & .4756328 & -228.094 & -63.97567 & -130.315 \\
\hline 2 & 1 & 34.4771 & .9287519 & -184.6116 & -61.5229 & -111.2774 \\
\hline 3 & 1 & 24.03339 & .8432045 & -122.0258 & -39.96661 & -73.13625 \\
\hline 4 & -197.0597 & 57.31162 & .0578553 & -134.391 & -26.68838 & -70.22354 \\
\hline
\end{tabular}

Tablo incelendiğinde 4 gecikme için sadece tam tanımlanmış GMM modeller için hesaplanan genel belirleme katsayısı (CD: $\mathrm{R}^{2}$ ), Hansen $\mathrm{J}$ istatistiği (tabloda $\mathrm{J}$ ), ve olasılık değeri (tabloda $\mathrm{j}$ pvalue), Andrews ve Lu tarafından (2001) GMM modeller için önerilen en çok olabilirlik (ML) temelli ve Hansen J istatistiğine dayanan Bayesyen bilgi kriteri (MBIC), Akaike Bilgi Kriteri (MAIC) ve Hannan Quinn bilgi kriteri (MQIC) değerleri görülmektedir. $\mathrm{R}^{2}$ değeri ilk üç gecikme için aynıdır. Hansen J istatistiği ve olasılık değerleri incelendiğinde "aşırı tanımlama kısıtlamaları geçerlidir” şeklinde olan $\mathrm{H}_{0}$ hipotezinin reddedildiği görülmektedir. (MQIC), (MAIC) ve (MBIC) kriterleri birinci gecikmede minimum olmaktadırlar. Uygun gecikme 1 olarak alınmıştır.

Tablo 5. Panel Vektör Otoregresif (VAR) Model Testi

\begin{tabular}{|c|c|c|c|c|c|c|c|}
\hline \multicolumn{2}{|l|}{} & Coef. & Std. Err. & $Z$ & $P>|z|$ & \multicolumn{2}{l|}{ [95\% Conf. Interval] } \\
\hline \multicolumn{2}{|l|}{ ddyy } & & & & & \\
\hline & ddyy & & & & & & \\
\hline & L1. & -.5053778 & .1434559 & -3.52 & 0.000 & -.7865463 & -.2242094 \\
\hline & dhdi & & & & & & \\
\hline & L1. & .0015249 & .0018872 & 0.81 & 0.419 & -.002174 & .0052237 \\
\hline & den & & & & & & \\
\hline & L1. & -95.12222 & 61.48609 & -1.55 & 0.122 & -215.6328 & 25.3883 \\
\hline & dict & & & & & & \\
\hline & L1. & 94.42243 & 140.4714 & 0.67 & 0.501 & -180.8965 & 369.7414 \\
\hline
\end{tabular}


Bu tabloda panel VAR modelinin iki eşitliğinin ileri ortagonal sapmalar kullanılarak GMM ile tahmini görülmektedir. Bu tahminci veri kaybına yol açmadığg için, birinci farklara dayanan GMM tahmincisine göre daha üstündür. Bu ekonometrik analiz neticesine göre bilgi ve iletişim teknolojisi endeksinin birinci gecikmesinde doğrudan yabancı yatırımları açıklamakta anlamlıdır. Bilgi ve iletişim teknolojileri endeksinin birinci gecikmesi insani gelişme endeksini açıklamakta anlamlıdır. Bilgi ve iletişim teknolojileri endeksi birinci gecikmesinde enerji endeksini açıklamada anlamlıdır.

Öngörü hatası ve varyans ayrıştırması için gerçekleştirilen ekonometrik analiz; varyans ayrıştırması sonuçlarının son gecikmede doğrudan yabancı yatırımlar değişkenine ilişkin öngörü hata varyansının \%98'i kendisinde meydana gelen şoklar tarafından belirlenirken $\% 0.02$ 'si insani gelişme endeksinde, \%0.09'u enerji kapasite endeksinde, \%0.03'ü de bilgi ve iletişim teknolojileri endeksinde meydana gelen şoklar tarafından belirlendiğini göstermektedir.

Gerçekleştirilen etki tepki analizi ekonometrik olarak \%95 güven düzeyinde, doğrudan yabancı yatırımlara verilecek şokun enerji kapasite endeksi, insani gelişme endeksi bilgi ve iletişim teknoloji kapasiye endeksi üzerindeki etkisi 4-5 yıl içerisinde yok olduğunu göstermektedir.

Gerçekleştirilen özdeğer istikrar koşulları ekonometrik analizi; tüm özdeğerlerin 1'den küçük ve grafiksel olarak birim çember içinde yer aldığını göstermektedir. Panel VAR özdeğer istikrar koşullarını sağlamaktadır.

Tablo 6. Granger Nedensellik Analizi

\begin{tabular}{|c|c|c|}
\hline \multicolumn{3}{|c|}{ Bağımlı Değişken: $d d y y$} \\
\hline Bă̆ımsız Dĕgişken(ler) & Chi-sq & Prob>chi-sq \\
\hline dhdi & 0.653 & 0.419 \\
\hline den & 2.393 & 0.122 \\
\hline dict & 0.452 & 0.501 \\
\hline Genel Panel & 17.145 & 0.001 \\
\hline
\end{tabular}

Tabloda görüldüğü üzere panel VAR Granger nedensellik testi için Wald testi yapılmıştır. Temel hipotez “dışlanan değişken eşitlikteki değişkenin Granger nedeni nedeni değildir” alternatif hipotez ise Granger nedeni olduğu şeklinde kurulmuştur. 


\subsection{Testlerin Sonuçları}

$\mathrm{Bu}$ çalışmada doğrudan yabancı yatırımlar bağımlı değişkeni üzerinde insani gelişme endeksinin, enerji kapasite endeksinin ve bilgi ve iletişim teknolojileri endeksinin etkileri 20002018 veri dönemi için analiz edilmiştir. Modelin homojenlik sınaması ile homojen olduğu belirlenmiştir. Değişkenlerin aynı seviyede durağan olmadıkları belirlenmiş ve aynı seiyede durağan olmayan serilerle yapılan anlizlerin yanıltıcı sonuçlar vereceği bilindiği için tüm değişkenlerin birinci dereceden farkları alınarak CD testi ile durağan oldukları test edilmiştir. Birimler arası korelasyonun varlığını tespit etmek kullanılacak birim kök testlerine karar vermede belirleyici olacağından, birimler arası korelasyonun testi Peseran CD testi ile belirlenmiş ve ikinci nesil birim kök testi gerçekleştirilmiştir. Panel VAR modelinin iki eşitliğinin ileri ortagonal sapmalar kullanılarak GMM ile tahmini yapılmıştır veri kaybı içermeyen bir yöntem olduğu için tercih edilmiştir. Uygulanan model genel olarak anlamlı bulunmamıştır. Ancak bilgi ve iletişim teknolojisi endeksinin birinci gecikmesinde doğrudan yabancı yatırımları açıklamakta anlamlıdır. Bilgi ve iletişim teknolojileri endeksinin birinci gecikmesi insani gelişme endeksini açıklamakta anlamlıdır. Bilgi ve iletişim teknolojileri endeksi birinci gecikmesinde enerji endeksini açıklamada anlamlıdır. Daha sonra öngörü hatası varyans ayrıştırması gerçekleştirilmiş bağımlı değişkendeki şokların bağımsız değişkenlerce açıklayıcılığı belirlenmiştir. Gerçekleştirilen etki tepki analizi ile değişkenlerde gerçekleşen şokların 4-5 y1l içerinde yok olduğu belirlenmiştir. Panel VAR modelinin özdeğer istikrar koşullarını sağladığı belirlenmiştir. Daha sonra homojen var modeli için Granger nedensellik analizi gerçekleştirilmiş, genel panel sonuçlarının anlamlı olmadığı tespit edilmiştir. DYY'nin bilgi ve iletişim teknoloji endeksi üzerinde pozitif anlamlı etki sahibi olduğu bunun yanı sıra bilgi iletişim teknolojileri endeksinin ve insani gelişme endeksinin karşılıklı ilişkilerinin pozitif ve anlamlı olduğunu birbirlerinin Granger nedeni olduğunu ayrıca bilgi ve iletişim teknolojileri endeksinin enerji kapasite endeksinin Granger nedeni olduğunu ortaya koymuştur.

\section{Genel Sonuç}

Döngüsel ekonomi çevresel sürdürülebilirlik, temiz ve yenilenebilir ulaşılabilir enerji kullanımı, sıfır atık hedefine yaklaşmak ve tüm bunları uygulayabilmek için teknoloji ve inovasyon unsurlarını gerektiren bir süreçtir. Bu süreç gelişmiş ve gelişmekte olan ayrıca farklı coğrafi bölgelerde yer alan ekonomilerde farklı kavramsal anlayışlar içerebilmektedir. $\mathrm{Bu}$ sürecin genel amacı, kaynak kullanımını GSYİH büyümesinden ayırmak için kaynak israfını önemli ölçüde azaltmak ve aynı zamanda çevresel etkilerin sınırlı olmasını ve refahın korunmasını sağlamaktır. Bu, daha azıyla daha çok ve daha iyi yapmanın bir örneğidir. 
1960'lardan itibaren bu kavram uluslararası kurum ve kuruluşların ve akademik çevrelerin de dikkatini çeken bir duruma gelmeye başlamıştır. Dünya nüfusunun artışıla sonlu kaynakların doğrusal ekonomi sisteminde üret-tüket-bertaraf et yaklaşımıyla insan ihtiyaçlarını karşılamada yetersiz kalacağı endişesi bunda pay sahibi olmuştur. Bir diğer ifadeyle döngüsel ekonomi atık yönetimi hiyerarşisinden kaynaklanan 3R kuralı (azalt, yeniden kullan ve dönüştür) insan refahını korurken eko-tasarımlar ile malzemeleri kullanımda tutarak atıkları azaltır, çevre dostu teknoloji ve inovasyonun üretimde geri dönüşüm süreçlerine dahil edilmesi temiz ve ulaşılabilir enerjinin kullanımını da arttırır ve böylelikle döngüsel ekonominin temel kavramlarından sürdürülebilirliği sağlamada olumlu aşama kaydedilmiş olur.

Araştırmada amaç; Türkiye ve 11 adet Latin Amerika örnekleminde döngüsel ekonomi ile bağlantılı olan insani gelişme, enerji ve teknoloji kavramlarının ekonomik büyüklük göstergelerine ne yönde ne düzeyde etki ettiğini 2000-2018 veri döneminde incelemektir. Çalışma döngüsel ekonomi göstergeleri ile ilişkilendirilebilen faktörlerin DYY girişleri üzerindeki belirleyiciliğini inceleyerek bu konuda literatüre katkı sağlamayı amaçlamaktadır. Uluslararası sermaye akımlarının bir türü olan doğrudan yabancı yatırımlar bu çalışmada ekonomik gösterge olarak alınmıştır. Bunun nedenlerinden bazıları doğrudan yabancı yatırım teorilerinde DYY'nin ekonomik büyümenin finansman kaynaklarından biri olarak genel kabul görmesi ve ekonomik büyüme ve DYY'ler arasında karşılıklı ilişkinin varlığının ekonometrik analiz içeren pek çok çalışmada doğrulanmış olmasıdır. Gerçekleştirilen ekonometrik analizde, genel panel VAR modeli anlamlı bulunmamış olmasına rağmen, teknolojinin enerji kapasite endeksi üzerinde etkisinin bulunması döngüsel ekonomiye geçiş sürecinde temiz enerji teknoloji ve inovasyonun önemli pay sahibi olduğu savını güçlendirmektedir. Bu çalışmada DYY'lerin bilgi ve iletişim teknolojileri üzerinde etki sahibi olduğunun nedensellik analiziyle belirlenmiş olması DYY'lerin teknolojinin etkin kullanımı ve teknoloji transferlerine katkıda bulunacağı tezini güçlendirmiştir. Ayrıca insani gelişme endeksi ve bilgi ve iletişim teknoloji kapasite endeksinin karşılıklı ilişkili bulunması; gelişmiş insani kalkınma düzeyini sağlamanın teknoloji kapasitesini geliştirecek ve yükseltecek olan beşeri sermayeyi de sağlayacağı düşüncesini güçlendirmiştir.

Döngüsel ekonominin gelişmiş ve gelişmekte olan ekonomilerde kendi yapısına uygun oluşturulan iş modelleri ile geliştirilmeye devam etmesinin gerekliliği; sonlu ve geri dönülemez doğrusal ekonomi işleyişinin sürdürülebilir olmaması nedeniyle, bu çalışmada ortaya konan çevresel sürdürülebilirlik, sıfır atık hedefi, temiz ve yenilenebilir enerji kullanımı, teknoloji ve inovasyon düzeyini sağlamayı amaçlayan çalışmalar program ve projeler örnek verilerek ortaya konmuştur. 


\section{KAYNAKÇA}

Addison, Tony and Almas Hesmati. 2003. "The New Global Determinants of FDI Flows to Developing Countries The Importance of ICT and Democratization”, WIDER (World Institute for Development Economics Research), Discussion Paper No. 2003/45 Helsinki, May 2003. https://www.wider.unu.edu/sites/default/files/dp2003-045.pdf

Albulescu, Claudiu Tiberiu, Aviral Kumar Tiwari, Seong-Min Yoon and Sang Hoon Kang. 2019. "FDI, income, and environmental pollution in Latin America: Replication and extension using panel quantiles regression analysis" Energy $\quad$ Economics, $\quad$ Elsevier, 2019. https://ideas.repec.org/a/eee/eneeco/v84y2019ics0140988319302853.html

Alfaro, Laura and Andrew Charlton. 2007. "Growth and the Quality of Foreign Direct Investment: Is All FDI Equal”, Harvard Business School Review, May 2007. http://www.hbs.edu/faculty/Publication\%20Files/07-072.pdf

Al-Iriani, Mahmoud (Corresponding Author Fatima Al-Shamsi). 2007. "Foreign Direct Investment and Economic Growth in the GCC Countries: A Causality Investigation Using Heterogeneous Panel Analysis.” Topics in Middle Eastern and North African Economies, electronic journal, Vol:9 No:1, pp.1-31, 2007.

Asongu, Simplice, Uduak S. Akpan, and Salisu R. Isihak, 2018. "Determinants of foreign direct investment in fast-growing economies: evidence from the BRICS and MINT countries.”, Finance Innov 4, 26, 2018. https://doi.org/10.1186/s40854-018-0114-0

Azman-Saini, Wan N.W., Siong Hook Law and Abd Halim Ahmad. 2010. "FDI and Economic Growth: New Evidence on the Role of Financial Markets", Economic Letters, Vol:107, pp.211-213, 2010.

Babaoğlu, Didem. 2005. “Sermaye Akımlarının Yönetimi: Türkiye’ye İlişkin Bir Değerlendirme”, Uzmanlık Yeterlilik Tezi, Danışman Selin Sayek Böke, Türkiye Cumhuriyet Merkez Bankası Piyasalar Genel Müdürlüğü Ankara, Kasım 2005.

Banco Central Do Brasil. 2020. "Direct Investment Report 2020”, Publication date: 01/12/2021, December 2020. https://www.bcb.gov.br/en/publications/directinvestmentreport

Baş̧̧ı Nur, Hayriye ve İlkay Dilber. 2017. “Gelişmekte Olan Ülkelerde Doğrudan Yabancı Yatırımları Belirleyen Temel Unsurlar”, Dokuz Eylül Üniversitesi İktisadi ve İdari Bilimler Fakültesi Dergisi, Cilt:32, Say1:2, ss.15-45, 2017

Batmaz, Nihat ve Halil Tunca. 2007. “Türkiye'de Doğrudan Yabancı Sermaye Yatırımlarının Bölgesel Belirleyicileri Üzerine Bir Eşbütünleşme Analizi (1992-2003)”, Sosyal Bilimler Araştırmaları Dergisi, Cilt: 1, ss.199-224, 2007.

Batmaz, Nihat ve Halil Tunca. 2005. Doğrudan Yabancı Sermaye Yatırımları ve Türkiye (1923-2003) (Birinci Basım), Beta Basım Yayım Dağıtım A.Ş., İstanbul 2005.

Batmaz, Nihat ve Sevinç Tekeli. 2009. Doğrudan Yabancı Sermaye Yatırımlarının Ekonomik Büyüme Üzerindeki Etkileri Polonya, Çek Cumhuriyeti, Macaristan ve Türkiye Örneği (1996-2006) (1.Baskı). Ekin Basım Yayın Dağıtım, Denizli, 2009.

Behname, Mehdi. 2012. "Foreign Direct Investment and Economic Growth: Evidence from Southern Asia", Atlantic Review of Economics, Volume.2, 2012.

Bengoa, Marta and Blanca Sanchez Robles. 2003. "Foreign Direct Investment, Economic Freedom And Growth: New Evidence From Latin America”, European Journal of Political Economy, Vol. 19, pp.529-545, 2003.

Berthelemy, Jean-Cladue and Slyvie Demurger. 2000. "Foreign Direct Investvent and Economic Growth: Theory and Application to China", Review of Development Economics, 4, s. 140-55, 2000.

Betancourt Morales, Claudia Marcela and Jhon Wilder Zartha Sossa. 2020. "Circular economy in Latin America: A systematic literature review" Business Strategy and Environment, Volume 29, Issue 6 Pages 24792497, September 2020. https://doi.org/10.1002/bse.2515

Blanco, Luisa R. 2012. “The Spatial Interdependence of FDI in Latin America”, World Development, Volume 40, Issue 7, Pages 1337-1351, 2012. https://doi.org/10.1016/j.worlddev.2012.02.003.

Blanco, Luisa R. Fidel Gonzalez, and Isabel Ruiz. 2013. "The Impact of FDI on CO2 Emissions in Latin America" (2013). Oxford Development Studies, 14(1), 104-121, March 2013. Available at SSRN: https://ssrn.com/abstract=2461035

Borensztein, Eduardo, Jose De Gregorio and Jong-Wha Lee. 1995. "How Does Foreign Direct İnvestment Affect Economic Growth”, NBER Working Paper Series, Working Paper Series No. 5057, National Bureau Of Economic Research Cambridge, MA02138, March 1995.

Brazil Trade and Investment Promotion Agency (ApexBrasil). 2019. "Investment Guide to Brasil 2019”, 2019. http://www.apexbrasil.com.br/uploads/Investment\%20Guide\%20to\%20Brazil\%20-\%202019.pdf

Brundtland, G. 1987. "Our Common Future, Oslo: General Assembly of the United Nations", 1987.

Candemir, Aykan. 2009. "Doğrudan Yabancı Sermaye Yatırımlarını Etkileyen Faktörler”, Ege Akademik Bakış, Cilt:9, Say1:2, ss.659-675, 2009. 
Choe, Jong Il. 2003. "Do Foreign Direct Investment and Gross Domestic Investment Promote Economic Growth?”, Review of Development Economics, Vol:7 No:1, pp. 44-57, 2003.

Chor, Foon Tang and Wah Tan Bee. 2015."The impact of energy consumption, income and foreign direct investment on carbon dioxide emissions in Vietnam”, Energy, Volume 79, Pages 447-454, ISSN 03605442,_2015. https://doi.org/10.1016/j.energy.2014.11.033.

Chowdhury, Abdur and George Mavrotas. 2006. "FDI and Growth: What Causes What?" World Economy, The World Economy, Volume 29, Issue 1, pp. 9-19, 2006.

Cüce, Hüseyin. 2018. "Endüstriyel Üretimde Döngüsel Çevre Politikaları”, Nevşehir Bilim ve Teknoloji Dergisi, Vol. $7(2) \quad$ ss.111-122, 2018. https://www.researchgate.net/publication/330022923_Endustriyel_Uretimde_Dongusel_Cevre_Politikal ari

Çiftci, Fatih ve Rıfat Yıldız. 2015.” Doğrudan Yabancı Yatırımların Ekonomik Belirleyicileri: Türkiye Ekonomisi Üzerine Bir Zaman Serisi Analizi, The Economic Determinants of Foreign Direct Investment: A Time Series Analysis on the Turkish Economy", Business and Economics Research Journal, Vol: 6, No: 4, pp. 71-95, 2015.

De Pascale, Angelina, Roberta Arbolino, Katarzyna Szopik-Depczynska, Michele Limosani and Giuseppe Ioppolo. 2021. "A systematic review for measuring circular economy: The 61 Indicators", Journal of Cleaner Production Vol. 281, 124942, 2021.

Economic Commission for Latin America and the Caribbean (ECLAC). 2018. "Foreign Direct Investment in Latin America and Caribbean 2018", United Nations Publication (LC/PUB.2018/13-P), Santiago, 2018. https://repositorio.cepal.org/bitstream/handle/11362/43690/7/S1800683_en.pdf

Ellen MacArthur Foundation (EMF). 2013. "Towards The Circular Economy Economic and Business Rationale for an Accelerated Transition” 2013. https://www.werktrends.nl/app/uploads/2015/06/Rapport_McKinsey-

Towards_A_Circular_Economy.pdf

Ellen MacArthur Foundation (EMF). 2015. "Towards a Circular Economy: Business rationale for an accelerated transition", $\quad$ First $\quad$ Published 2015. https://www.ellenmacarthurfoundation.org/publications/towards-a-circular-economy-business-rationalefor-an-accelerated-transition

Emir, Mustafa ve Melih Kutlu. 2014. "Relationship Between Foreign Direct Investment And Economic Growth In Developing Countries, Gelişmekte Olan Ülkelerde Doğrudan Yabancı Yatırımlar ile Ekonomik Büyüme İlişkisi”, Journal of Economics, Finance and Accounting - (JEFA), Volume: 1 Issue: 1, Year: 2014 pp.38-45.

Erdoğan, Ali. 2016. Gelişmekte Olan Ülkelerde Doğrudan Yabancı Sermaye Yatırımları ve Türkiye Örneği (2.Basım) Mart 2016, Nobel Akademik Yayıncılık Eğitim Danışmanlık Tic. Ltd. Şti. Ankara, 2016.

Geissdoerfer, Martin, Marina P.P. Pieroni, Daniela C.A. Pigosso and Khaled Soufani. 2020. "Circular business models: A review", Journal of Cleaner Production Vol.277, 123741, 2020. https://www.sciencedirect.com/science/article/abs/pii/S0959652620337860?via\%3Dihub

Haug, Alfred A. and Meltem Ucal. 2019. "The role of trade and FDI for CO2 emissions in Turkey: Nonlinear relationships," Energy Economics, Elsevier, vol. 81(C), pages 297-307, 2019.

Hsiao, Cheng and Yan Shen. 2003. "Foreign Direct Investment and Economic Growth: The Importance of Institutions and Urbanization”, Economic Development and Cultural Change, Vol. 51, No. 4, 2003.

Institut Montaigne. 2016. "The Circular Economy: Reconciling Economic Growth With The Environment" November 2016. https://www.institutmontaigne.org/ressources/publications-pdfs/circular-economypolicy-paper.pdf

Kar, Muhsin ve Fatma Tatlısöz. 2008. “Türkiye'de Doğrudan Yabancı Sermaye Hareketlerini Belirleyen Faktörlerin Ekonometrik Analizi”, KMU İ̈BF Dergisi, Say1: 14, Y11: 10, 2008.

Karagöz, Kadir. 2007. "Türkiye’de Doğrudan Yabancı Yatırım Girişlerini Belirleyen Faktörler: 1970 - 2005”, Journal of Yasar University, Vol.2, No:8, pp.927-948, 2007.

Karimi, Mohammad Sharif and Zulkornain Yusop. 2009. "FDI and Economic Growth in Malaysia", MPRA Paper No. 14999, 26 March 2009. _http://mpra.ub.uni-muenchen.de/14999/

Karluk, Rıdvan. 1999. “Türkiye Ekonomisi”, Beta Basım YayınDağıtım A.Ş., İstanbul, 1999.

Kirchherr, Julian, Denise Reike and Marko Hekkert. 2017. "Conceptualizing the circular economy: An analysis of 114 definitions”, Resources, Conservation and Recycling, Volume 127, Pages 221-232, ISSN 0921-3449, 2017. https://doi.org/10.1016/j.resconrec.2017.09.005.

Koyuncu, Fatma Turan. 2011. "Doğrudan Yabancı Yatırımların İktisadi Büyümeye Etkisi: Türkiye İçin Bir Ekonometrik Analiz", EconAnadolu 2011: Anadolu International Conference in Economics II June 1517, Eskişehir, Turkey, 2011.

Li, Xiaoying and Liu Xiaming. 2004. "Foreign Direct Investment and Economic Growth: An Increasingly Endogenous Relationship”, Worm Development, Vol. 33, No: 3, pp. 393-407, 2005. 
Liu, Yiming, Yu Hao and Yixuan Gao. 2017. "The environmental consequences of domestic and foreign investment: Evidence from China", Energy Policy 108 (2017) 271-280, 2017.

Martínez, Juan Daniel. 2021. "An overview of the end-of-life tires status in some Latin American countries: Proposing pyrolysis for a circular economy", Renewable and Sustainable Energy Reviews, Volume 144, 111032, 2021. https://www.sciencedirect.com/science/article/abs/pii/S1364032121003221?via\%3Dihub

Meadows, Donella H. Dennis L. Meadows, Jorgen Randers and William W. Behrens III. 1972. "The Limits To Growth, A Report for the Club of Rome's Project on The Predicament of Mankind" Universe Books, New York, 1972. https://www.clubofrome.org/publication/the-limits-to-growth/

Mencinger, Jože. 2003. "Does Foreign Direct Investments Always Enhance Economic Growth?”, Kyklos, International Review for Social Sciences, Vol 56, 2003.

Newman, Carol, John Rand, Theodore Talbot and Finn Tarp. 2015. "Technology Transfers, Foreign Investment And Productivity Spillovers”, European Economic Review, Vol.76, pp.168-187, 2015.

Okuyan, H.Aydın ve Erman Erbaykal. 2007. "Gelişmekte Olan Ülkelerde Doğrudan Yabancı Yatırımlar ve Ekonomik Büyüme İlişkisi”, Ekonomik Yaklaşım, Cilt: 19, Sayı: 67, ss. 47-58, 2007.

Önder, Hüseyin. 2018. "Sürdürülebilir Kalkınma Anlayışında Yeni Bir Kavram: Döngüsel Ekonomi”, Dumlupınar Üniversitesi Sosyal Bilimler Dergisi, Vol.57, pp.196-204. Retrieved from https://dergipark.org.tr/tr/pub/dpusbe/issue/38899/416907

Örnek, İbrahim. 2008. "Yabancı Sermaye Akımlarının Yurtiçi Tasarruf ve Ekonomik Büyüme Üzerine Etkisi: Türkiye Örneği”, Ankara Üniversitesi Siyasal Bilgiler Fakültesi Dergisi, Cilt: 63, Say1: 2, ss.199-217, 2008.

Özcan, Burcu ve Ayşe Arı. 2010. "Doğrudan Yabancı Yatırımların Belirleyicileri Üzerine Bir Analiz: OECD Örneği”, İstanbul Üniversitesi İktisat Fakültesi Ekonometri ve İstatistik Dergisi, Ekonometri ve İstatistik Say1:12 ss. 65-88 Y1l: 2010.

Provin, Ana Paula, Ana Regina de Aguiar Dutra, Isabel Cristina Aguiar de Sousa e Silva Gouveia, and e Anelise Leal Vieira Cubas. 2021. "Circular economy for fashion industry: Use of waste from the food industry for the production of biotextiles", Technological Forecasting and Social Change, Volume 169, 2021, 120858, https://doi.org/10.1016/j.techfore.2021.120858

Pesaran, Mohammad Hashem. 2004. General Diagnostic Tests for Cross Section Dependence in Panels. Cambridge Working Papers in Economics no. 0435, 2004.

Pesaran, Mohammad Hashem. 2007. A simple panel unit root test in the presence of cross-section dependence. J. Appl. Econ. 22, 265-312, 2007.

Pincelli Pimentel, Isabella, Armando Borges de Castilhos Júnior, Marcelo Seleme Matias and Emília Wanda Rutkowski. 2021. "Post-Consumer Plastic Packaging Waste Flow Analysis For Brazil: The Challenges Moving Towards A Circular Economy", Waste Management Vol. 126, pp.781-790, 2021. https://www.sciencedirect.com/science/article/abs/pii/S0956053X21002026?via\%3Dihub

Ranta, Valtteri, Leena Aarikka-Stenroosa and Juha-Matti Vaisanen. 2021. "Digital technologies catalyzing business model innovation for circular economy-Multiple case study", Resources, Conservation \& $\begin{array}{llll}\text { Recycling } & \text { Vol.164, } & 105155, & 2021 .\end{array}$ https://www.sciencedirect.com/science/article/pii/S0921344920304729?via\%3Dihub

Reike, Denise, Walter J.V. Vermeulen and Sjors Witjes. 2018. "The circular economy: New or Refurbished as CE 3.0? - Exploring Controversies in the Conceptualization of the Circular Economy through a Focus on History and Resource Value Retention Options" Resources, Conservation and Recycling, Volume 135, Pages 246-264, 2018. https://www.sciencedirect.com/science/article/pii/S0921344917302756?via\%3Dihub

Roy, Atrayee Ghosh and Hendrik F. Van den Berg. 2006. "Foreign Direct Investment and Economic Growth: A Time-Series Approach”, University of Nebraska - Lincoln DigitalCommons@University of Nebraska Lincoln Economics Department Faculty Publications Economics Department 4-1-2006. http://digitalcommons.unl.edu/cgi/viewcontent.cgi?article=1031\&context=econfacpub

Seker, Fahri, Hasan Murat Ertugrul and Murat Cetin. 2015. "The impact of foreign direct investment on environmental quality: A bounds testing and causality analysis for Turkey, Renewable and Sustainable Energy Reviews, Volume 52, Pages 347-356, https://www.sciencedirect.com/science/article/abs/pii/S1364032115007650

Şahinöz, Ahmet. 1998. "Türkiye Ekonomisinin Sektörel Analizi”, Turhan Kitabevi, İstanbul, 1998.

T.C. Cumhurbaşkanlığı Yatırım Ofisi. 2020. "Türkiye'de Uluslararası Doğrudan Yatırımlar 2019”, https://www.invest.gov.tr/tr/library/publications/lists/investpublications/kitapcik-turkiyede-dogrudanyabanci-yatirimlar.pdf

T.C. Dışişleri Bakanlığı. 2021. “Türkiye'nin Latin Amerika ve Karayiplere Yönelik Politikası ve Bölge Ülkeleri ile İlişkileri”, Dış politika, Bölgeler, Latin Amerika ve Karayipler, https://www.mfa.gov.tr/i_turkiye_nin-latin-amerika-ve-karayiplere-yonelik-politikasi-ve-bolge-ulkeleri-ile-iliskileri.tr.mfa

T.C. Buenos Aires Büyükelçiliği Ticaret Müşavirliği. 2015. “Arjantin Ülke Raporu 2014”, Buenos Aires, 2015. 
T.C. Ekonomi Bakanlığı Teşvik ve Uygulama ve Yabancı Sermaye Genel Müdürlüğü. 2015.“Uluslararası Doğrudan Yatırımlar 2014 Yılı Raporu”, Eylül 2015.

T.C. Ticaret Bakanlığı. 2019. "Yurtdışı Yatırım Raporu 2019”, Ankara Serbest Bölgeler, Yurtdışı Yatırım ve Hizmetler Genel Müdürlüğ̈̈, Ankara, Haziran 2019. https://ticaret.gov.tr/data/5c4ac3db13b876297ce9a568/Yurtd\%C4\%B1\%C5\%9F\%C4\%B1\%20Yat\%C4 \%B1r\%C4\%B1m\%20Anketi\%20-\%202019\%20Sonu\%C3\%A7\%20Raporu.pdf

Tatoğlu Yerdelen, Ferda. 2017. "Panel Veri Ekonometrisi” (Birinci Basım), Beta Basım Yayım, Ankara, 2017.

Tatoğlu Yerdelen, Ferda. 2017. "Panel Zaman Serileri Analizi” (Birinci Basım), Beta Basım Yayım, Ankara, 2017.

Terliksiz, Levent. 1988. "Yabancı Sermaye Yatırımları ve Türkiye, Dünyada ve Türkiye'de Yabancı Sermaye Yatırımları ve Beklentiler Yarışması, YASED Yayını, Yayın No: 33, 237-248, İstanbul, 1988.

The Organisation for Economic Co-operation and Development (OECD). 2008. "Benchmark Definition of Foreign Direct Investment Fourth 2008. http://www.oecd.org/daf/inv/investmentstatisticsandanalysis/40193734.pdf

The Organisation for Economic Co-operation and Development (OECD). 2010. "Glossary Of Foreign Direct Investment Terms And Definitions” OECD Economic Globalisation Indicators, OECD Publishing, 2010. http://www.oecd.org/daf/inv/investmentfordevelopment/2487495.pdf

The World Bank. 2013. "Regulating Foreign Direct Investment in Latin America Indicators of investment regulations and options for investment climate reforms", A report of the FDI Regulations project Global Indicators and Analysis Department The World Bank Group with CAF - Development Bank of Latin America October 2013. http://iab.worldbank.org/ /media/FPDKM/IAB/Documents/Regulating-FDI-inLatin-America.pdf

Türkiye Cumhuriyet Merkez Bankası, (TCMB). 2014. "Uluslararası Yatırım Pozisyonu Raporu Aralık 2014", Ankara, 2014. http://www.tcmb.gov.tr/wps/wcm/connect/17a19712-b68a-4943-ba4fe8b618b5cc72/uyprapor_2014.pdf?MOD=AJPERES\&CACHEID=ROOTWORKSPACE17a19712b68a-4943-ba4f-e8b618b5cc72

Türkiye Cumhuriyet Merkez Bankası, (TCMB). 2021. "Uluslararası Yatırım Pozisyonu Şubat 2021", Veri Yönetişimi ve İstatistik Genel Müdürlüğü Ödemeler Dengesi Müdürlüğü, 2021. https://www.tcmb.gov.tr/wps/wcm/connect/cb23c98d-d9a5-465f-8c9c9f84b533aaf8/uyp.pdf?MOD=AJPERES\&CACHEID=ROOTWORKSPACE-cb23c98d-d9a5-465f8c9c-9f84b533aaf8-nzEXs.W

Umoh, Okon J., Augustine O. Jacob and Chuku A. Chuku. 2012. "Foreign Direct Investment and Economic Growth in Nigeria: An Analysis of the Endogenous Effects", Current Research Journal of Economic Theory, Vol.4, No:3, pp.53-66, 2012.

United Nations. 1973. "Report of The United Nations Conference on the Human Environment" Stockholm, 546 June 1972.

United Nations. 1987. "Report of the World Commission on Environment and Development: Our Common Future", 1987, Oxford University Press, 1987.

United Nations Conference on Trade and Development, (UNCTAD). 2018. "World Investment Report 2018, Investment And New Industrial Policies", United Nations Publication, 2018. https://unctad.org/system/files/official-document/wir2018_en.pdf

United Nations Conference on Trade and Development, (UNCTAD). 2019. "World Investment Report 2019, Special Economic Zones" United Nations Publicatıon, 2019. https://unctad.org/system/files/officialdocument/wir2019_en.pdf

United Nations Development Programme. 2020. “İnsani Gelişme Raporu 2020 Önümüzdeki Sınır: İnsani Gelişme ve Antroposen 2020 İnsani Gelişme Raporu'ndaki Ülkelerle İlgili Açıklama Notu Türkiye”, 2020. https://www.tr.undp.org/content/dam/turkey/UNDP-TR-BRIEFING-NOTE-TURKEY-TR.pdf

Xavier, Lúcia Helena, Ellen Cristine Giese, Ana Cristina Ribeiro-Duthie and Fernando Antonio Freitas Lins. 2019. "Sustainability and the circular economy: A theoretical approach focused on e-waste urban mining", Resources Policy Available online 23 August, 101467, 2019. https://0210d2zrf-y-https-wwwsciencedirect-com.cbu.proxy.deepknowledge.io/science/article/pii/S0301420717305433

Yalçın, Özkan ve Nilüfer Negiz. 2020. “Türkiye’de Kentsel Alanlarda Döngüsel Ekonomi Uygulamaları Üzerine Bir Yazın İncelemesi”, Akademia Doğa ve İnsan Bilimleri Dergisi Academia Journal of Nature and Human Sciences, 2020. https://dergipark.org.tr/tr/pub/adibd 